\title{
ADJUSTING A STRATEGIC CASH-FLOW MODEL FOR BANGLADESHI SMALL AND MEDIUM ENTERPRISES: THE ART OF SURVIVING COVID-19 EMERGENCY
}

\author{
Ariful Islam \\ Putra Business School (AACSB-Accredited), Serdang, Malaysia \\ farhan_ctg2012@yahoo.com \\ Adil Mansoor \\ Putra Business School (AACSB-Accredited), Serdang, Malaysia \\ adilmansoor5@gmail.com \\ Mostafizur Rahman \\ Putra Business School (AACSB-Accredited), Serdang, Malaysia \\ mostafiz.man@gmail.com \\ Sazali Abd Wahab \\ Putra Business School (AACSB-Accredited), Serdang, Malaysia \\ sazali@putrabs.edu.my
}

\begin{abstract}
Purpose: In a very short period, the worldwide pandemic sparked by the COVID-19 has not only taken multiple lives but has also imposed extreme restrictions on both the private and business activities. The purpose of the study at this point is to provide a broader interpretation of how a flexible cash-flow structure of various strategic interventions will enable Bangladeshi SMEs to endure through the emergency. Design/Methodology/Approach: The study has embraced a qualitative approach on basis of online focus group discussion with the support of a professional facilitator. The data collection process includes 09 participants from various fields, such as Academia, SMEs, Media, and NGOs. Findings: Because SMEs are operating in uncertain conditions, the analysis from the discussions suggests that an adjustable integration of various ranges of cash-flow management initiatives, such as cash flow targets, clear payment terms, use of technology, revisit variable cost, extend payables, and government schemes can help SMEs to endure throughout this turbulent time. Research limitation: Prior empirical attempts are subsequently required to inquiry about the proposed model for SMEs from different perspectives. Also, besides, a smaller sample size creates an issue with generalizability. The moderator, intentionally or inadvertently, may inject his personal biases into the participants' exchange of ideas. Practical implications: The formulated model provides recommendations for SMEs and on how to remain competitive through resilience and renewal strategies. Originality/Value: This article is the first to configure a strategic cash-flow management model for Bangladeshi SMEs to harness the entrepreneurial potential of the pandemic.
\end{abstract}

Keywords: Bank card, COVID-19, Digitalization, Innovation, Liquidity, Mobile Wallet. 


\section{INTRODUCTION}

SMEs serve alternative channels for global growth (Gamidullaeva et al., 2020). There is an epidemic at the time of writing of a deadly new coronavirus known as COVID-19 which has the potential to influence SMEs' financial status (Bartik et al., 2020). This infectious disease has now spread to over 100 countries across the globe with its epicenter in Wuhan City in Hubei Province of China (World Health Organisation, 2020; Zhu, 2020). It is transmitted through a person who contracted the disease caused when one sneezes or coughs direct contact with the respiratory droplets (UNICEF, 2020). It is often spread when healthy human contact objects infected with the infection. The current situation at COVID19 is more or less equivalent to the SARS outbreak of 2003. The crisis may theoretically have an impact on SMEs' financial outputs.

In fact, SMEs are the bloodline of Bangladesh's economy which directly creates jobs for 7.8 million people and provides 31.2 million livelihoods (Hossain et al., 2020). These enterprises contribute $25 \%$ of our GDP but may contribute more (BBS, 2016). The COVID-19 pandemic has infected every field of life and industry, but the toughest blow has struck Bangladesh's already vulnerable SMEs. SMEs are more vulnerable because they tend to have smaller sources of resources, fewer assets, and smaller production levels than larger companies (OECD, 2020). Extreme disturbances are incidents that disturb the normal distribution of goods or resources within a system such as pandemics (Blackhurst et al., 2011). Extreme disturbances again have catastrophic effects on the performance of the business and supply chain (Wamba et al., 2018), and hence on the productivity, profitability, and survival of SMEs. Bangladesh's small and medium-sized businesses have suffered as they are reliant on a limited cash period that was disrupted by supply chain instability and lack of revenue. Some new studies indicate that $28 \%$ of Bangladeshi SMEs have experienced a significant fall in their sales by more than $50 \%$ (LIGHTCASTLE, 2020). SMEs are unable to sustain funding and business operations due to the ongoing lockdown. According to the statistics, $68 \%$ of SMEs indicated that if the lockout lasts for more than four months, they would have to permanently shut down their business activities. SMEs are building livelihoods in Bangladesh and, if they fail, we will be moving into deeper economic shock with more and more people falling below poverty. Because of the value of cash flow in such periods, SMEs should automatically establish a cash-flow management system as part of their overall business risk and continuity planning (Syriopoulos, 2020). In matter of fact, business survival/failure leading to growth is connected to net amount of cash inflows and outflows from SME's operational activities (Amuzu, 2010). Cash flow management, perceived to be the cornerstone of an enterprise for short and long-term survival, has remained an ongoing obstacle for SMEs (Karadag, 2015). It is clear that having cash on hand makes a difference for small and medium-sized businesses in Bangladesh when the COVID-19 


\section{ADJUSTING A STRATEGIC CASH-FLOW MODEL FOR BANGLADESHI SMALL AND MEDIUM ENTERPRISES: THE ART OF SURVIVING COVID-19 EMERGENCY}

pandemic's ripple effects escalate internationally and cannot be calculated before the situation stabilizes.

Triggered by the fact that the sustainability of SMEs is vital to the global economy (Storey, 2016), it is critical for SMEs to have strategies in place to ensure continuity of operation, described as "identifying and managing threats that threaten to interrupt critical cash flow processes" (Mihai-Yiannaki et al., 2012; Syriopoulos, 2020). About the importance of using the proactive and efficient cash-flow mechanism to maintain business stability during severe disruptions (and thus COVID-19), Bangladeshi SMEs and managers have little to no advice about how to handle cash-flows for such disruptions in organizations. Past academic contributions of Butler and Gray (2006), Niemimaa (2015), Pal et al., (2014), Madrid-Guijarro et al.,(2016), Serrasqueiro et al., (2018), and Tangsucheeva et al., (2014) have analyzed the mechanism of cash flow in restoring small and medium enterprises from various crisis scenarios. Also, the latest studies of Syriopoulos (2020), Cowling et al., (2020), and Lu et al., (2020) tried to assist SME's survival process during the COVID-19 emergency by analyzing about internal financial management or the importance of precautionary saving leading to business success. However, we contend that none of them offered a suitable direction of cash-flow control layout for ownersmanagers or policymakers given the black swan edges of the COVID-19 pandemic considering developing regions. Thus, the authors intend to design a robust digitalization-focused cash-flow structure to assist Bangladeshi SMEs' endurance on the basis of identified strategic measures that can interplay or work together in the field of survival leading to sustained business growth.

The overarching purpose of this exploratory analysis is to contribute to the aforementioned research stream on the socio-technical approaches to sustainability focused on the Bangladesh context. This motivational aspect promotes strategic appraisal and business revitalization through a "innovative" direction that meets the interests of all mankind and life. Practices of innovation within SMEs are a big justification for government funding, because funding services and activities encourage and inspire SMEs to step forward through crises (Songling et al., 2018). Striving exclusively for the technical or digital transition is inadequate to gain a sustainable competitive edge (Vajjhala and Strang 2018). Thus, small and medium-sized companies must be viewed as a socio-technical environment where technological progress must go hand and hand with the continuous advancement of operational facets. Improved operational skills through effective cash-flow control of SMEs often contribute to enhanced regional development through capability acquisition and work creation (Rahatulain, 2020). Hence this study can also be seen as a step towards improving Bangladeshi SMEs' sustainable business dynamics. 


\section{ADJUSTING A STRATEGIC CASH-FLOW MODEL FOR BANGLADESHI SMALL AND MEDIUM ENTERPRISES: THE ART OF SURVIVING COVID-19 EMERGENCY}

\section{RESPONSE OF SMES DURING CRISIS}

A variety of other words, including accident, business disruption, tragedy and emergency, have been used interchangeably with the phrase 'crisis' in industry (Herbane, 2010). Selection policy approaches for crisis management consider both the internal and external climate (Litovchenko, 2012). Here, it is concluded that the formulation of main policy recommendations for the crisis should also take into consideration the time factor and the needs of all involved parties. In reality, the crisis communication strategies (crisis management strategy) take a special approach (Noratikah et al., 2017). There are three aims of the crisis management approach (Coombs and Hollady, 2012): influencing crisis attributions, shifting corporate attitudes in crisis, and reducing the negative impact created by a crisis. Again, crisis plannings are at this stage identifying protocols for sustaining and/or restoring essential operations. They are supposed to develop strategies, protocols, and an organizational framework for crisis management (Alcalde-Heras et al., 2019; Henderson, 2008). These plans identify the functions and duties of agencies, management units and staff in crisis, the equipment, strategies and procedures that are needed. Wenzel et al. (2020)'s analysis yet again leads to four policy solutions to the crisis: retrenchment, perseverance, creativity, and escape given the COVID-19 pandemic scenario. The importance of these responses is correlated with different time horizons which unfold potential net benefits in the short, medium, long(er) run, or at any time.

The required strategic outline is essentially related to the company's mid-term objective, raising its achievements by tackling vulnerabilities, risks, assets, and prospects (Beliaeva et al., 2020). SMEs may be more susceptible to crisis-related incidents due to capital shortage problems, uncertain marketplace, and other factors. However, SMEs may have several benefits linked to adaptability, technical capabilities, growth programs, consumer partnerships (Herbane, 2013; Hong et al., 2012). Innovation refers to undertaking structural renewal in response to crises according to the context of our exploratory research. As previous studies show, emergencies open doors for competitive renewal even for small and medium-sized companies that adhere rigidly to their policies under business as usual circumstances. This is so because emergencies induce a retrospective state that encourages managers and staff to overcome the limits of what they consider to be feasible. Given that long-lasting crises, in particular, leave irrevocable marks in the business environment that makes it difficult to revert to the previous order, creativity or innovation is a necessary, if not essential, strategic response to the crisis to ensure firm sustainability over the long term (Ivanus and Repanovici, 2016).

From another viewpoint, the crisis administrators or managers believe in the importance of a favorable, pre-crisis reputation. A shielding effect that prevents an organization during a crisis may be generated by the prior reputation (Timothy and Holladay, 2006). For SMEs who communicate directly with clients, 


\section{ADJUSTING A STRATEGIC CASH-FLOW MODEL FOR BANGLADESHI SMALL AND MEDIUM ENTERPRISES: THE ART OF SURVIVING COVID-19 EMERGENCY}

the reputational factor has become a very significant element in contemporary economies. Reputation, along with other intrinsic elements related to consumer partnerships, creativity, and company policy (Dospinescu et al., 2020), is an inclusive representation of the responsible actions of businesses and of policies planned and applied. As a consequence, a favorable past credibility means that following a crisis, a company loses less and rebounds sooner. In response to numerous challenges or emergencies, organizations need to follow reputational policies and strategies targeted at crisis prevention and collaboration (Frandsen et al., 2016).

For SMEs, each crisis is a source of awareness (Mikušová and Horváthová, 2019). A professionally assessed crisis management approach includes evaluating decisions and responses and their consequences, examining the attitudes of crisis team members and employees in general, and more. It should not only be about catching the suspects. However, considering the omnipresence and scale of crises, such as the ongoing COVID-19 pandemic outbreak, we contend that further analysis is required in times of crisis to explore strategy-formulation. In particular, while complexity has fallen out of favor in many strategic management models (Alvarez et al., 2018), it is an important part of crisis responses. That makes it difficult, if not impossible, for managers to know ex-ante what strategic approach would lead firms to survive a crisis and rebound from the shock (Pearson and Clair, 1998). Therefore, we urge future studies to explore more closely the internal and external enablers (and disablers) that lead managers and workers to respond (in) adequately to the situational circumstances triggered by crises (Amoiradis and Stankova, 2020).

\section{CASH-FLOW MANAGEMENT}

Cash flow management is a collection of techniques that operate upon a company's short-term liquidity. At the same time, it affects certain variables and processes that automatically transform into currency, with the ultimate goal of growing the business' profitability and enhancing the management of working capital (Gupta et al., 2014; López-Gracia et al., 2008). The management of cash-flows can be viewed from two distinct perspectives: simple cash management and advanced cash management (Carpenter and Guariglia, 2008). Basic cash management is a technique that optimizes the level of liquid funds to be maintained by a company and eliminates trading cycle breaks or gaps due to lack of cash. They can also develop a high liquidity investment strategy that can be transformed into cash at low transactional costs to help the assets held by the organization (López-Gracia et al., 2008).

Cash-flow control is the cornerstone of a short- and long-term sustainability corporate enterprise (Ahmad, 2016; Munusamy et al., 2010); obsessed with both the short-term and long-term financial targets (Evans, 2012); and calculated by analyzing the cash-flow statement (Megaravalli and 


\section{ADJUSTING A STRATEGIC CASH-FLOW MODEL FOR BANGLADESHI SMALL AND MEDIUM ENTERPRISES: THE ART OF SURVIVING COVID-19 EMERGENCY}

Sampagnaro, 2019). As per Aminu (2012), cash flow management ties together activities relevant to cash transfer, collection management, and liquidity management that include the purchase and disposition of treasury reserves and their eventual control, a policy to spend cash surpluses to optimize profits and cover deficits at minimal expense. Managing cash-flow is a continuing problem for SME owners or managers, according to CIMA, since they pay less attention to it and therefore do not recognize the effect of cash scarcity on resource turnover and company activities (Botten, 2007). The investigation of Amuzu, (2010) related business success/failure to the number of net cash inflows and outflows from the activities of a company as the inability to produce cash from its operations may cause it to borrow more money or dispose of its capital assets to satisfy its obligations but may lead to unintended bankruptcy if this situation continues over time.

In addition, there are issues that the frequent use of these credit or debit cards can have an immense effect on the cash flow control of the business. The use of bank cards can also be a true opportunity, leading to the fluidization of national and international money flows for the economies of developed or emerging countries (Nguyen and Cassidy, 2018). In fact, the technology of bank cards has quickly progressed from" classic "to contactless and virtual cards (Wang, 2008), allowing customers greater control over purchases and improved speed of transactions (Eyuboglu and Sevim, 2017). SMEs currently need access to a variety of faster options for payment, particularly digital solutions such as cards, digital payments, and peer-to-peer transactions (Dospinescu et al., 2019; Shofawati, 2019). By having easy access to funds on the receipt side, a precise location of cash reserves, faster reconciliation, and visibility into payment efficiency, it helps to control cash flow. It is not a guarantee to realize the pledge of bank cards given Bangladesh's SME situation. Getting there requires that policymakers invest in the right technology, that regulators promote adoption that banks advocate it, and that SMEs concentrate on digitizing their payments.

\section{THEORETICAL UNDERPINNING}

In the view of the theory of readiness, it emphasizes that organizations vulnerable to emergencies and unexpected incidents should develop a commitment to cope with such emergencies. This theory further stressed the idea of decision-makers, power, planning, and systemic decentralization in times of catastrophe as processes to expect or plan for the unexpected without anticipation make it difficult for individuals to forecast the unexpected at the time of such crisis (Voogd, 2004; Smith, 2004). On the other hand, the sense-making theory also stresses the mechanism of social structures that takes place at the intersection of conflicting messages and the continuity of the actions of individuals, as it includes the creation of rational interpretations that lead and direct people to what they do in times of crisis and 


\section{ADJUSTING A STRATEGIC CASH-FLOW MODEL FOR BANGLADESHI SMALL AND MEDIUM ENTERPRISES: THE ART OF SURVIVING COVID-19 EMERGENCY}

abhorrent events (Weick et al., 2005). In this sense, Al-Dabbagh (2020) introduced a new decisionmaking paradigm to solve the COVID-19 crisis which may be a starting point for the implementation of training programs to improve the capacity of decision-makers to take decisions in periods of crisis and catastrophe. Decision-makers require patience and experience at all levels of the crisis in order to play productive and active positions in efficient cash-flow management for SMEs' sustainability. Here, Al Eid and Arnout (2020) outline the decision-maker as a significant contributor who acts as a connection between staff, the plans of the company, and future expectations.

\section{METHODOLOGY}

In management researches, social media or online networks have increasingly replaced numerous types of contact channels, such as mobile, email, or even face-to-face interviews (Bronstein et al., 2016; Phan and Airoldi, 2015). Thus, the increasing interest in tech-oriented new media and social networks is expanding research ramifications in an emerging field of multidisciplinary nature that brings together a wide variety of academics from diverse disciplines (Bunea et al., 2019).

Now, in terms of access to information and assessment of various findings and ideas, the social media network considered online focus groups has become a tool in the whole data collection process. A professional moderator orchestrated an interactive debate on how Bangladeshi SMEs might withstand the current time of hardship caused by the COVID-19 epidemic among a small group of respondents, enabling them to react spontaneously to the Cash-flow management strategy.

The study has addressed the following key research question:

"Can we articulate our ideas on the best cash flow management techniques for SMEs in Bangladesh to survive this tumultuous period?"

Initially, a total of 12 respondents who are the members of the Rotary Club of Bangladesh have been invited through WhatsApp for the group discussion session. Rotary is where neighbors, colleagues, and problem solvers exchange experiences, join leaders, and take steps to bring about positive change. When the participants are first approached, details on the research are given to them. Later, the focus group is made up of 09 members (those who agreed) from diverse sectors such as Academia, SMEs, Media, and NGOs (Non-Government Organization). Here NGOs are a sub-division of organizations founded by citizens and free from government influence. Since focus group discussion depends on the willingness and ability of participants to provide relevant information, the methodology accepts a purposive judgmental sampling approach (Morgan, 2002). The group's 45-minute collaborative session helped stimulate in-depth perspectives and conversations. The whole process involves the correct use of probing questions, follow-up questions, and exit questions. The data collection method here also 
includes non-verbal data dependent on the position, mood, silences, hesitations, and sound of voice tone of the respondent. The data coding was later carried out by initial coding and emphasis coding, while the use of content processing is geared towards formal information coding by detailing it into many categories. Results collected were shared with research respondents by participant confirmation to verify results that improve the report's legitimacy rating. The research also supported the practice of obtaining secondary understanding through numerous newspapers, magazines, blogs, e-books, documentaries, and similar publications of journals. The researchers have found the government and the non-government data to achieve the research's key objective.

\section{RESULT ANALYSIS}

TABLE 1. DEMOGRAPHIC INFORMATION OF PARTICIPANTS

\begin{tabular}{|c|c|c|c|}
\hline \multicolumn{2}{|c|}{ Professional Experiences } & \multicolumn{2}{|c|}{ Academic Qualification } \\
\hline Years & No of Participants & Name of Certification & No of Participants \\
\hline $0-5$ years & 4 & Degree & 4 \\
\hline $5-10$ years & 3 & Masters & 4 \\
\hline $10+$ years & 2 & PhD & 1 \\
\hline \multicolumn{3}{|c|}{ Total Number of Participants=09/ Male-7, Female-2 } \\
\hline \multicolumn{3}{|c|}{ Source: Compiled from online focus group discussion } \\
\hline
\end{tabular}

In the focus group session, a total of 09 participants expressed their thoughts. Of those 09, 7 are male, and 2 are female. The highest percentage of respondents is in the 30-40 age range and holds at least one-degree credential as an advanced qualification. Most participants possess between 0 and 5 years of practical experience in their respective fields. Based on their more than 10 years of practical experience, two of the participants expressed their awareness and ideas about the study purpose of the concern.

We first transcribe all the focus group statements or comments during the study. For all the relevant questions, the key ideas in the answers are noted. The analytical method of the key ideas has since been carried out to recognize ideas that appear again and again. We introduce critical thinking at this juncture regarding these recurrent key ideas in order to define significant cash-flow management strategies (Table 2). Cash-flow is synonymous with sustainability for virtually any company, despite the volatile time. The aim of this section is to define the fundamental variables that can help the cash-flow management system of small and medium-sized companies and decide how to handle and sustain this 
Islam, A., Mansoor, A., Rahman, M., Abd Wahab, S.

\section{ADJUSTING A STRATEGIC CASH-FLOW MODEL FOR BANGLADESHI SMALL AND} MEDIUM ENTERPRISES: THE ART OF SURVIVING COVID-19 EMERGENCY

continuing challenge due to COVID-19. The online group discussion results in these emergency times revealed a lot of efficient methods to handle cash-flow.

TABLE 2: MAJOR STRATEGIES DETECTED FOR CASH-FLOW MANAGEMENT DURING COVID-19 CRISIS

\begin{tabular}{|l|c|}
\multicolumn{1}{|c|}{ Detected Strategies } & $\begin{array}{c}\text { Number of Participants Identified with } \\
\text { The Initiatives }\end{array}$ \\
\hline [a] Cash flow targets & 7 \\
[b] Clear payment terms & 7 \\
\hline [c] Use of technology & 8 \\
\hline [d] Revisit variable cost & 6 \\
\hline [e] Extend payables & 5 \\
\hline [f] Government schemes & 9 \\
\hline
\end{tabular}

Source: Compiled from online focus group discussion

\section{[a] Cash flow targets}

The analysis of the responses reflected that one method of managing cash-flow is to plan and sustain a cash-flow related forecast. Some participants consider checking this regularly to include a reliable forecast for the next six to 12 months. Participant A[06] indicates at this point-

"..... setting credit controller goals is a perfect way to guarantee that the required focus is paid and offers a sense of motivation and ownership to hit and beat those goals."

A cash flow monitoring model acts as an early warning indicator to the potential financial performance of an organization by applying a forensic microscope on cash flows in a range of hypothetical conditions (Ding et al., 2016, May). There are several analytical applications specialized in cash-flow modeling during this pandemic, but Excel can also be used efficiently. Many SMEs in Bangladesh do not have the financial resources to withstand short-term challenges or threats to their companies. It is important to have a cash-flow analysis tool on hand to determine the viability of an organization over a given timeframe.

\section{[b] Clear payment terms}

The majority of participants say that it is necessary for the SMEs involved to survive this pandemic to develop transparent payment conditions from the outset. Participant A [01] claims-"..... if you don't want to know what the terms of payment are, it's hard to know what you're charged," 
In particular, the terms of payment should be used to help firms collect payments regularly ( $\mathrm{Li}$ et al., 2018). Cash on Delivery (COD) or Payable on Receipt is helpful to the company owner as it accelerates the process of payment. In comparison, a concept such as "Max 30" implies that the user or vendor deposit within 30 days. If they deposit within 10 days, though, they will earn a 2 per cent discount. You will of course change those words if you wish.

For example, you could sweeten the incentive by offering a $5 \%$ discount if the invoice is paid within a week. During this turbulent period, if work, situation or client structures change, it's perfectly acceptable to introduce new payment terms. SMEs also need to invoice clients as soon as the work is completed. For example, if the payment is charged within a week, you could sweeten the opportunity by giving a $5 \%$ discount. Where job, condition or consumer systems change during this tumultuous time, adding new payment conditions is perfectly appropriate. SMEs would still need to charge consumers until the job is complete.

One respondent tagged A [09] explicitly agrees as-"... issuing your email invoice would mean it's going to get there automatically, and you'll have a record of it being submitted."

\section{[c] Use of technology}

Cash-flow monitoring during this pandemic can be made even simpler by technologies (Guembour and Nadira, 2018). The results from the analysis show that cloud-based accounting during this recession is the greatest time-saver for SMEs, enabling them to function more efficiently, free up time, and maintain a closer track of company cash-flow. It will eliminate the troubling burden of all those details being backed up. Any of the participants often think that owners or administrators can monitor their accounts on the go with a laptop, tablet, or cell phone to stay up to date with volatile financial conditions. To accept the new standard needs rewards and strategies that are acceptable. Our study claims that increased communication is a focused company requires through emergencies, accompanied by financial help in the transition to processes and structures that are enabled by technologies. Besides, charges should be made to the consumer as quickly as possible. As participant A [01] says-

"... try not to be billed via cheque as it will lead to complications until the money gets into your bank account....mobile or online transfers are a much safer choice."

As the shutdown is pushing people to stay inside houses, companies need to turn to online platforms. Linking with mobile wallets, MFS (Mobile Financial Service), DFS (Internet Financial Service), and Automated Supply Chain Management can help create medium-term strategies for resolving the severity of the crisis. Indeed, the examined discussion suggests that, during this situation, SMEs will need a systemic cash-flow approach to succeed in the long run. Initiating a Strategic Digital Transition 
partnership in particular regions will be one way. Solutions would include: a) Digital Supply Chain integration, b) Digital Finance System, and c) Credit access.

\section{[d] Revise variable cost}

The reflected participants added that the variable cost of the elimination aspect is also a better way to reduce the cash outflows quickly than to rely on the fixed costs. There are, of course, the usual flexible cost-reduction mechanisms, such as enforcing travel prohibitions and non-essential conference limits (which might also be in effect as a means to control staff safety), implementing caps, and putting limitations on discretionary expenditures such as recreation and T\&D. Some participants also argue that when labor is a significant cost line in SMEs, consider avenues that might help reduce spend to avoid getting to a situation where layoffs are required. Look for ways, for example, to minimize contract labor, and redistribute jobs to permanent workers. Encourage staff to use up the available balance of leave and reduce balance sheet liabilities. And propose giving volunteer, or even spontaneous, leave without pay to conserve cash if appropriate.

\section{[e] Extend payables}

Participants believe that one way to maintain working resources or capitals by allowing paying similar vendors to take too long. Some businesses which arbitrarily decide to postpone their payments and impose the extension on their suppliers, particularly when they are stuck with inventory, they are unable to supply through margins that have been impacted. Of course, such a strategy would possibly destroy the relationships with the supply. And worse, it could rob supply chain suppliers of the cash they need to sustain their activities, which could lead to late delivery and quality concerns, regardless of the supplier relationship burden applied. Our results suggest negotiating with vendors or suppliers to establish a contract in which both parties will operate. There may also be cases where you need to hurry up payables with a crucial product on the verge of bankruptcy to maintain supply chain stability and avert a crucial interruption.

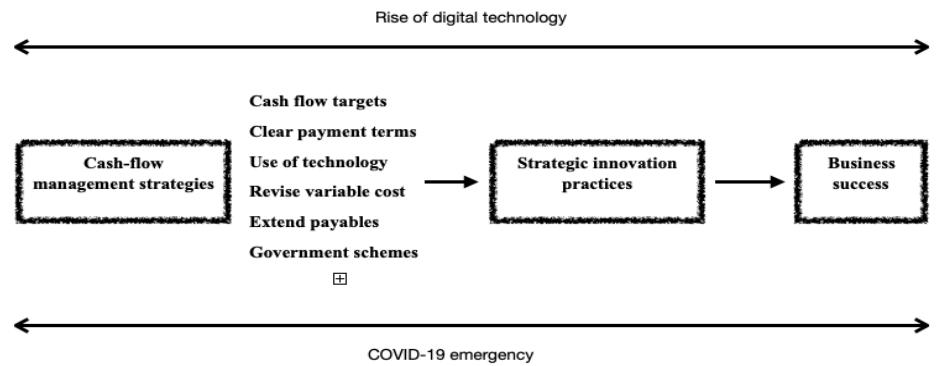

FIGURE 1. PROPOSED CASH-FLOW MANAGEMENT MODEL FOR BANGLADESHI SMES Source: Formulated by authors 


\section{ADJUSTING A STRATEGIC CASH-FLOW MODEL FOR BANGLADESHI SMALL AND MEDIUM ENTERPRISES: THE ART OF SURVIVING COVID-19 EMERGENCY}

\section{[f] Government schemes}

Bangladeshi government had asked companies to shutter channels to protect the public. By providing economic stimulus programs the same government is now taking action to support those enterprises. The government would have incentives for promoting more private investment to support economic growth and domestic demand, while simultaneously increasing public spending (KPMG, 2020). The participants reflected that having access to this financial assistance from the government is a good way to alleviate cash-flow issues. Bangladesh has set aside a total of USD 2.35 BN for SMEs as a stimulus package for economic revamping (IMF, 2020). On March 31, the government unveiled a funding plan for export-oriented sectors from BDT 50 BN (approx. USD 595 m) (KPMG, 2020). This provides salary support and 2-year loan insurance at 2 percent interest to factory owners. The repo interest rate of Bangladesh Bank dropped from 6 percent to 5.75 percent. Present stimulus packages available by banks, though, are based on current partnerships with SMEs that many of the smaller players won't have. This means they will not be able to take advantage of such concessional loans.

In addition, our research advances to inform stakeholders that it is necessary to stay updated about how the company is doing (Linkov et al., 2020). Main stakeholders are-employees, investors, and buyers. On the other hand, banks are getting more innovative and seeking solutions to aid businesses struggling, and consumers are able to inject new money to fund their portfolio firms. Financiers would be more likely to contribute if they can see that a consistent growth approach has been established by the policymakers. Based on the study, the participants assume it is the right time for Bangladeshi SMEs to introduce pipeline near-ready developments or innovations. Many small and medium-sized businesses are averse to creativity, but just as kindness drives compassion, empathy produces empathy. Customers who usually will pick up technologies will now be thankful for innovative and updated products/services even though they are launched before all the kinks are worked out. In reality, the cash flow management framework needs to be an important part of a firm's overall COVID-19 risk evaluation and short-term response planning (Kraus et al., 2020). Not only should owners or managers of SMEs rely on sales and inventory levels to optimize working capital: they need to care about the whole environment and supply chain. Squeezing products out of service cannot do any good and may potentially add considerable risk if it merely transfers the responsibility to a seller or consumer. The same is true for receivables and payables (Jobst, 2006). It is important to carefully consider the effect of determining behavior on the upstream and downstream stages. High-level financial risk assessments should be done on all important, sole-source vendors to detect concerns before they become issues. In certain situations, where a vital business is at risk, owners or administrators of small and medium-sized 
companies will also decide to purchase a share in the company or absorb the company to secure the supply chain and keep products and services running.

\section{IMPLICATION FOR RESEARCHES}

SMEs implementing cash-flow management configuration to ensure the continuation of operations needs a structural rethinking of their business processes. The effects of the developed model on function, organization, and results would be significant to scholars. Another paradigm is to match this concept with the corporate plan of the SMEs to cope with the COVID-19 repercussions. A further improvement of the socio-technical approach in the study of cash-flow model implementation will be the cash-flow turn of socio-materiality, which exposes the concept of separate cash-flow policy, function, and organizations through (i) agreeing that social and resources should not be segregated (Perera, 2008) or (ii) insisting on the imbrication of a social and technical approach that could be distinct but should be viewed as interlocking in order to produce successful effects (Leonardi et al., 2012, Anagnostopoulos et al., 2018). These lenses may help researchers understand the role that strategy facet cash-flow management model plays in creating an environment that promotes creative innovation, translating COVID-19 problems into opportunities for performance improvement and societal impact development.

Finally, using the idea of 'organizational ambidexterity' (O'Reilly and Tushman, 2013) to analyze the application of the cash-flow model by SMEs to resolve COVID-19 problems would be beneficial for researchers. In fact, there have been several studies on how big firms become ambidextrous, but they lag behind in terms on SMEs (Lubatkin et al., 2006). It is proposed that ambidexterity is a complex skill that can support small and medium-sized enterprises build sensing, capturing and transforming operations for cash-flow management processes and resolve the COVID-19 problems.

\section{IMPLICATION FOR PRACTICES}

Necessary requirements in the SMEs have to be established for the creation, application, and successful use of the cash flow management mechanism. Therefore, due to COVID-19 SMEs facing various obstacles and complexities, the actors involved would need to establish several equations for future strategic actions. Equations building apart from supplying managers with knowledge of their multiple strategic decisions according to their skills and project goals; scenarios considered to be opportunities to activate and enhance organizational learning processes (Kovoor-Misra and Olk, 2015). In the current situation, firms are evaluating their position in society and embracing a stakeholder strategy where their task is to assist those whose families have been impacted by. SMEs must also 
follow a constructive, collaborative strategy, which would enhance the daily lives of local, national, and global communities. In the age of pandemic emergencies, decision-makers are asked to make and implement difficult decisions. Thus, practitioners and managers need to follow understandings learned from SMEs using the cash-flow management model to maintain market stability during COVID-19.

In addition, it can test the mentality of treating the problem somehow not only as a negative factor but also as an opportunity for progress or development before a new future crisis arises. Society will benefit in several different ways from a better proactive cash-flow model at SMEs. It may minimize the number of workers fired, or even discourage the formation of certain bankrupt SMEs.

\section{FINAL THOUGHTS, LIMITATIONS AND FUTURE DIRECTION OF THE STUDY}

The COVID-19 crisis has created new problems on an almost unprecedented scale for strategicmanagement researchers. Clearly, the pandemic's devastating effects are infinite. To survive the time of the COVID-19 crisis, the study developed a cash-flow management model for Bangladeshi SMEs. The proposed structure is also geared towards encouraging, disseminating, and enhancing the theoretical understanding of business management among practitioners of the various disciplines. We also argued in favor of SMEs adopting a socio-technical approach when it comes to their cash-flow techniques to cope with COVID-19 based issues when sustaining their operations. However, the sequence of discrete actions and an understanding of their origin, terminology, and obligations will become a valuable method for the longevity of the cash flow management process defined here.

Our suggested strategic cash-flow management outline definitely retains the operational potential to optimize available capital and minimize financial losses for SMEs when necessary during the COVID-19 pandemic, contributing to the study's research question. We conclude that the proposed model presents the SMEs with an innovative ambidextrous benefit that can either take advantage of or seek financial resources to ensure successful cash-flow control of its survival process. Nevertheless, throughout the COVID-19 pandemic, emerging technological or digital innovations have gradually become the strongholds of businesses (Seetharaman, 2020). We realize intuitively that not only will the recession leave many companies fighting for survival, but it will also push others to search for new strategic directions. At this point, the delivered cash-flow model acts as a supporting framework for recent technical developments. It is important to understand the appraisal of this model against their need to follow sustainable market paradigms based on digital innovation. In order to ensure sustainable growth in the long term, these obtained findings related with the adjustments of cash-flow management and operations are necessary and crucial for SMEs. 


\section{ADJUSTING A STRATEGIC CASH-FLOW MODEL FOR BANGLADESHI SMALL AND MEDIUM ENTERPRISES: THE ART OF SURVIVING COVID-19 EMERGENCY}

Moreover, in light of the outcomes of the explorative investigation, we recommend as below for the successful deployment of the obtained cash-flow model:

[a] We agree in spirituality as a strategic business element to address a situation that is interwoven with a firm's principles and purposes. Our formulated cash-flow handling configuration can give better output if integrated with the Islamic crisis management outline proposed by Al Eid and Arnout (2020). This Islamic strategy is to address the emergency of COVID-19 in several practical measures which are: to identify the crisis and to establish its causes, then to describe its effects, then to follow strategies to deal with it and to prepare to overcome this crisis.

[b] Need to provide necessary training to the SME's decision-makers about crisis management.

[c] Increasing awareness level of decision-makers about the roles required of them when managing crises.

Indeed, sustainability and resilience must become an important part of all contingency planning, as collectivity success depends on the power and durability of the weakest link(s) (Blatt, 2009). It is important to reinforce the social foundation institutions and structural infrastructures on which others rely so that they can withstand the effect of the next crisis, regardless of timing and origin, and sustain their dependents (Etemad, 2020). Management preparation, simulation to assess the viability and efficacy of pandemic situations for alternate contingency measures, and their viability and usefulness, among others, are of vital importance in the context of Bangladeshi SMEs for the efficient execution of this cash-flow model. Even, in an attempt to help businesses and raise the bottom line, the government should be reducing the tax rate and providing incentives to firms in hard-hit industries. In addition, exemption [or deferment] from withholding tax payments can be a timely initiative for SMEs in particular, exemption from VAT on revenue and expenses for the current and next fiscal year. In the off possibility that one thing COVID-19 has shown unmistakably is that curiosity in digitalization is not a privilege. Innovation is not only about overcoming this crisis; it is about building a viable enterprise that can become competitive and grow in the "new standard".

The key drawback of the study suggests a relatively limited sample size, so observations cannot be clarified reliably by generalized population. Moreover, the survey was designed with only participants from Bangladesh, so repeating the analysis with local participants in another country can provide interesting outcomes. But comparing SMEs from various countries about the effects of the COVID-19 pandemic and evaluating their cash-flow management strategies based on government crisis legislation may be an insightful research approach for the near future. Here, the authors aren't saying the 'just right' solution. However, a broader interpretation has been advocated which provides views with structure and meaning. We welcome more creation or explanation. However, they can state the functional utility of the 


\section{ADJUSTING A STRATEGIC CASH-FLOW MODEL FOR BANGLADESHI SMALL AND MEDIUM ENTERPRISES: THE ART OF SURVIVING COVID-19 EMERGENCY}

presented system, which has already been validated by its implementation to several small-scale manufacturing SMEs in Bangladesh.

\section{REFERENCES}

Ahmad, N. N. (2016). Cash management practices in micro and small businesses in Malaysia. Journal of Education and Social Sciences, 4(1):331-335.

Alcalde-Heras, H., Iturrioz-Landart, C., \& Aragon-Amonarriz, C. (2019). SME ambidexterity during economic recessions: the role of managerial external capabilities. Management Decision.

Al Eid, N. A., \& Arnout, B. A. (2020). Crisis and disaster management in the light of the Islamic approach: COVID-19 pandemic crisis as a model (a qualitative study using the grounded theory). Journal of Public Affairs, e2217.

Alvarez, S., Afuah, A., \& Gibson, C. (2018). Editors' Comments: Should Management Theories Take Uncertainty Seriously?. Academy Of Management Review, 43(2), 169-172.

Al-Dabbagh, Z. S. (2020). The Role of Decision-maker in Crisis Management: A qualitative Study Using Grounded Theory (COVID-19 Pandemic Crisis as A Model). Journal of Public Affairs, e2186.

Aminu, Y. (2012). An analysis of proposed framework on impact of working capital management on the profitability of selected Manufacturing companies listed on the Nigerian stock exchange. Journal of Economics and Behavioral Studies, 4(12): 730-736.

Amoiradis, C., \& Stankova, M. (2020). THE SYSTEMIC CRISIS AND THE NEED FOR SUSTAINABILITY: AN OVERVIEW. Management Research \& Practice, 12(1).

Amuzu, M. S. (2010). Cash flow ratio as a measure of performance of listed companies in emerging economies: The Ghana example. Unpublished PhD dissertation. Retrieved from http://stclements. edu/grad/gradmaxw. pdf.

Anagnostopoulos, I. (2018). Fintech and regtech: Impact on regulators and banks. Journal of Economics and Business, 100(1): 7-25.

Bartik, A. W., Bertrand, M., Cullen, Z., Glaeser, E. L., Luca, M., \& Stanton, C. (2020). The impact of COVID-19 on small business outcomes and expectations. Proceedings of the National Academy of Sciences, 117(30): 17656-17666.

BBS. (2016). Bangladesh Bureau of Statistics SME Report. Retrieved from http://203.112.218.65:8008/

Beliaeva, T., Shirokova, G., Wales, W., \& Gafforova, E. (2020). Benefiting from economic crisis? Strategic orientation effects, trade-offs, and configurations with resource availability on SME performance. International Entrepreneurship and Management Journal, 16(1): 165-194.

Blackhurst, J., Dunn, K. S., \& Craighead, C. W. (2011). An empirically derived framework of global supply resiliency. Journal of business logistics, 32(4): 374-391.

Blatt, R. (2009). Resilience in entrepreneurial teams: Developing the capacity to pull through. Frontiers of Entrepreneurship Research, 29(11): 1-8.

Botten, N. (2007). CIMA Official Learning System Management Accounting Business Strategy. Butterworth-Heinemann.

Bronstein, J., Gazit, T., Perez, O., Bar-llan, J., Aharony, N. and Amichai-Hamburger, Y. (2016), "An examination of the factors contributing to participation in online social platforms", Aslib Journal of Information Management, 68(6): 793-818. 


\section{ADJUSTING A STRATEGIC CASH-FLOW MODEL FOR BANGLADESHI SMALL AND MEDIUM ENTERPRISES: THE ART OF SURVIVING COVID-19 EMERGENCY}

Bunea, O. I., Popescu, R. I., \& Zamfir, A. I. (2019). Social Media As A Component Of The Value Chain To Gain Competitive Advantage In Sales. In Proceedings of the INTERNATIONAL MANAGEMENT CONFERENCE (Vol. 13, No. 1, pp. 702-710). Faculty of Management, Academy of Economic Studies, Bucharest, Romania.

Butler, B. S., \& Gray, P. H. (2006). Reliability, mindfulness, and information systems. MIS quarterly, 211-224.

Carpenter, R. E., \& Guariglia, A. (2008). Cash flow, investment, and investment opportunities: New tests using UK panel data. Journal of Banking \& Finance, 32(9): 1894-1906.

Timothy Coombs, W., \& Holladay, S. (2006). Unpacking the halo effect: reputation and crisis management. Journal Of Communication Management, 10(2): 123-137.

Coombs, T., \& Hollady, S. J. (2012). The handbook of crisis communication. New York: Wiley.

Cowling, M., Brown, R., \& Rocha, A. (2020). < ? covid19?> Did you save some cash for a rainy COVID19 day? The crisis and SMEs. International Small Business Journal, 0266242620945102.

Ding, S., Wang, D., Wang, Y., \& Sun, Z. (2016, May). Study on the Financial Crisis Warning Based on Cash Flow. In 2016 International Conference on Applied Mathematics, Simulation and Modelling. Atlantis Press.

Dospinescu, N., Dospinescu, O., \& Tatarusanu, M. (2020). Analysis of the Influence Factors on the Reputation of Food-Delivery Companies: Evidence from Romania. Sustainability, 12(10): 4142.

Dospinescu, O., Anastasiei, B., \& Dospinescu, N. (2019). Key factors determining the expected benefit of customers when using bank cards: An analysis on millennials and generation $Z$ in Romania. Symmetry, 11(12): 1449.

Etemad, H. (2020). Managing uncertain consequences of a global crisis: SMEs encountering adversities, losses, and new opportunities. Journal of International Entrepreneurship, 18(2): 125144.

Evans, P. B. (2012). Embedded autonomy: States and industrial transformation. Princeton University Press.

Eyuboglu, K., \& Sevim, U. (2017). Determinants of contactless credit cards acceptance in Turkey. Uluslararası Yönetim Iktisat ve Işletme Dergisi, 13(2): 331-346.

Frandsen, F., Johansen, W., \& Salomonsen, H. H. (2016). Responding to institutional complexity: Reputation and crisis management in Danish municipalities. Scandinavian Journal of Public Administration, 20(2): 7-38.

Gamidullaeva, L., Vasin, S., \& Wise, N. (2020). Increasing small- and medium-enterprise contribution to local and regional economic growth by assessing the institutional environment. Journal Of Small Business And Enterprise Development, 27(2): 259-280.

Guembour, A., \& Nadira, R. (2018). Role of Communication and Technology in Crisis Management. European Journal of Engineering and Formal Sciences, 2(2): 96-100.

Gupta, J., Wilson, N., Gregoriou, A., \& Healy, J. (2014). The value of operating cash flow in modelling credit risk for SMEs. Applied Financial Economics, 24(9): 649-660.

Henderson, D. M. (2008). The Comprehensive Crisis and Continuity (COOP) template for public \& private schools (K-12) on CD-ROM: Risk and impact analysis, continuity of plans and crisis/risk management plan. Brookfield: Rothstein.

Herbane, B. (2013). Exploring crisis management in UK small-and medium-sized enterprises. Journal of Contingencies and Crisis Management, 21(2): 82-95. 


\section{ADJUSTING A STRATEGIC CASH-FLOW MODEL FOR BANGLADESHI SMALL AND MEDIUM ENTERPRISES: THE ART OF SURVIVING COVID-19 EMERGENCY}

Herbane, B. (2010). Small business research - Time for a crisis-based view. International Small Business Journal: Researching Entrepreneurship, 28(1): 43-64.

Hong, P., Huang, C., \& Li, B. (2012). Crisis management for SMEs: insights from a multiple-case study. International Journal of Business Excellence, 5(5): 535-553.

Hossain, M., Yoshino, N., \& Taghizadeh-Hesary, F. (2020). Optimal branching strategy, local financial development, and SMEs' performance. Economic Modelling.

IMF. (2020). Retrieved from https://www.imf.org/en/News/Articles/2020/05/29/pr20226-bangladesh-imfexec-board-approves-us-732m-disbursement-to-address-the-covid19-pandemic

Ivanus, G., \& Repanovici, A. (2016). SME's innovation strategy for business continuity and crisis management. Transilvania University of Brasov, 9 (58): 155-162.

Jobst, A.A. (2006), "Asset securitisation as a risk management and funding tool: What small firms need to know", Managerial Finance, 32(9): 731-760.

Karadag, H. (2015). Financial management challenges in small and medium-sized enterprises: A strategic management approach. EMAJ: Emerging Markets Journal, 5(1): 26-40.

Kovoor-Misra, S. and Olk, P. (2015), "Leader culpability, hopelessness, and learning during organizational crises", Leadership \& Organization Development Journal, 36(8): 990-1011.

Kraus, S., Clauss, T., Breier, M., Gast, J., Zardini, A., \& Tiberius, V. (2020). The economics of COVID19: initial empirical evidence on how family firms in five European countries cope with the corona crisis. International Journal Of Entrepreneurial Behavior \& Research, 26(5): 1067-1092.

Leonardi, P. M. (2012). Materiality, sociomateriality, and socio-technical systems: What do these terms mean? How are they different? Do we need them. Materiality and organizing: Social interaction in a technological world, 25.

Li, R., Skouri, K., Teng, J. T., \& Yang, W. G. (2018). Seller's optimal replenishment policy and payment term among advance, cash, and credit payments. International Journal of Production Economics, 197(1): 35-42.

LIGHTCASTLE. (2020). COVID-19: Impact on Bangladesh's SME Landscape. Dhaka. Retrieved from http://("COVID-19: Impact on Bangladesh's SME Landscape - LightCastle Partners", 2020)

Linkov, I., Carluccio, S., Pritchard, O., Ní Bhreasail, Á., Galaitsi, S., Sarkis, J., \& Keisler, J. (2020). The case for value chain resilience. Management Research Review, ahead-of-print(ahead-of-print).

Litovchenko, Y. (2012). The choice and justification the strategy of enterprise crisis management. Biznes Inform, 12(1): 308-312.

Lu, Y., Wu, J., Peng, J., \& Lu, L. (2020). The perceived impact of the Covid-19 epidemic: evidence from a sample of 4807 SMEs in Sichuan Province, China. Environmental Hazards, 1-18.

Lubatkin, M. H., Simsek, Z., Ling, Y., \& Veiga, J. F. (2006). Ambidexterity and performance in small-to medium-sized firms: The pivotal role of top management team behavioral integration. Journal of management, 32(5): 646-672.

López-Gracia, José, and Francisco Sogorb-Mira. "Testing trade-off and pecking order theories financing SMEs." Small Business Economics 31.2 (2008): 117-136.

Madrid-Guijarro, A., García-Pérez-de-Lema, D., \& Van Auken, H. (2016). Financing constraints and SME innovation during economic crises. Academia Revista Latinoamericana De Administración, 29(1): 84-106.

Megaravalli, A., \& Sampagnaro, G. (2019). Predicting the growth of high-growth SMEs: evidence from family business firms. Journal Of Family Business Management, 9(1): 98-109. 


\section{ADJUSTING A STRATEGIC CASH-FLOW MODEL FOR BANGLADESHI SMALL AND MEDIUM ENTERPRISES: THE ART OF SURVIVING COVID-19 EMERGENCY}

Mihai-Yiannaki, S., \& Stokes, P. (2012). Special issue on: risk management for SMEs and corporations. International Journal Of Organizational Analysis, 20(4).

Mikušová, M., \& Horváthová, P. (2019). Prepared for a crisis? Basic elements of crisis management in an organisation. Economic research-Ekonomska istraživanja, 32(1): 1844-1868.

Morgan, D. L. (2002). Focus group interviewing. Handbook of interview research: Context and method, 141-159.

Munusamy, J., Chelliah, S., \& Mun, H. W. (2010). Service quality delivery and its impact on customer satisfaction in the banking sector in Malaysia. International journal of innovation, management and technology, 1(4): 398.

Nguyen, O. D. Y., \& Cassidy, J. F. (2018). Consumer intention and credit card adoption in Vietnam. Asia Pacific Journal of Marketing and Logistics.

Niemimaa, M. (2015). Interdisciplinary review of business continuity from an information systems perspective: toward an integrative framework. Communications of the Association for Information Systems, 37(1), 4.

Noratikah, M. A., Aizza Maisha, D. A. A., \& Mus Chairil, S. (2017). Crisis response strategy and crisis types suitability: A preliminary study on $\mathrm{MH} 370$. Paper presented at the International conference on communication and media: An international communication association regional conference (iCOME'16), Kuala Lumpur, Malaysia, 33.

O'Reilly III, C. A., \& Tushman, M. L. (2013). Organizational ambidexterity: Past, present, and future. Academy of management Perspectives, 27(4): 324-338.

OECD. (2020). Retrieved from https://read.oecd-ilibrary.org/view/?ref=119_119680di6h3qgi4x\%26title=Covid-19_SME_Policy_Responses

Pal, R., Torstensson, H., \& Mattila, H. (2014). Antecedents of organizational resilience in economic crises-an empirical study of Swedish textile and clothing SMEs. International Journal of Production Economics, 147(1): 410-428.

Pearson, C. M., \& Clair, J. A. (1998). Reframing crisis management. Academy of Management Review, 23(1): 151-182.

Perera, O. (2008). How material is ISO 26000 social responsibility to small and medium-sized enterprises (SMEs)? Winnipeg: International Institute for Sustainable Development.

Rahatulain, A. (2020). Sustainable evolution of SMEs in response to socio-technical emergence (Doctoral dissertation, KTH Royal Institute of Technology).

Seetharaman, P. (2020). Business models shifts: Impact of Covid-19. International Journal of Information Management, 54, 102173.

Serrasqueiro, Z., Leitão, J., \& Smallbone, D. (2018). Small-and medium-sized enterprises (SME) growth and financing sources: Before and after the financial crisis. Journal of Management \& Organization, $1-16$.

Shofawati, A. (2019). The Role of Digital Finance to Strengthen Financial Inclusion and the Growth of SME in Indonesia. KnE Social Sciences, 389-407.

Smith, K. (2004). Environmental Hazards: Assessing Risk and Reducing Disaster. London: Routledge

Songling, Y., Ishtiaq, M., Anwar, M., \& Ahmed, H. (2018). The role of government support in sustainable competitive position and firm performance. Sustainability, 10(10): 3495.

Storey, D. J. (2016). Understanding the small business sector. Routledge. 
Syriopoulos, K. (2020). The Impact of Covid-19 on Entrepreneurship and SMES. Journal of the International Academy for Case Studies, 26(2): 1-2.

Tangsucheeva, R., Shin, H., \& Prabhu, V. (2014). Stochastic Models for Cash-Flow Management in SME. In Encyclopedia of Business Analytics and Optimization (pp. 2288-2298). IGI Global.

UNICEF. (2020). Novel coronavirus (COVID-19) outbreak: What you should know. Retrieved from https://www.unicef.org/indonesia/novel-coronavirus-covid-19-outbreak-what-you-should-know

Vajjhala, N. R., \& Strang, K. D. (2018). Sociotechnical challenges of transition economy SMEs during EU integration. In Doing Business in Europe (pp. 295-313). Springer, Cham.

Voogd, H. (2004). Disaster prevention in Urban Environment. European Journal of Spatial Development, 12(1):1-20.

Wamba, S., Gunasekaran, A., Papadopoulos, T., \& Ngai, E. (2018). Big data analytics in logistics and supply chain management. The International Journal Of Logistics Management, 29(2): 478-484.

Wang, Y. M. (2008). Determinants affecting consumer adoption of contactless credit card: an empirical study. CyberPsychology \& Behavior, 11(6): 687-689.

Weick, K., Sutcliffe, K., \& Obstfeld, D. (2005). Organizing and the process of sense making. Organization Science, 16(4): 409.

Wenzel, M., Stanske, S., \& Lieberman, M. (2020). Strategic responses to crisis. Strategic Management Journal.

World Health Organization. (2020). Coronavirus disease (COVID-19) oubreak. Retrieved from http://www.euro.who.int/en/health-topics/health-emergencies/coronavirus-covid-19/novelcoronavirus2019-ncov

Zhu, N. (2020). A novel coronavirus from patients with pneumonia in China. N Engl J Med, 20(8): 727733. 